\title{
Poor Acetabular Component Orientation Increases Revision Risk in Metal-on-Metal Hip Arthroplasty
}

\author{
J. Tuomas Tauriainen, MS ${ }^{\text {a }}$, Tuukka T. Niinimäki, MD, $\mathrm{PhD}^{\mathrm{a}}$, Jaakko L. Niinimäki, MD, $\mathrm{PhD}{ }^{\mathrm{b}}$, Tomi O.P \\ Nousiainen, MD ${ }^{\text {a }}$, Juhana I. Leppilahti, MD, PhD ${ }^{\text {a, * }}$ \\ ${ }^{a}$ Division of Orthopaedic and Trauma Surgery, Department of Surgery, Oulu University Hospital, Medical Research Center, University of Oulu, Oulu, Finland \\ ${ }^{\mathrm{b}}$ Department of Diagnostic Radiology, Institute of Diagnostics, Oulu University Hospital, Medical Research Center, University of Oulu, Oulu, Finland
}

\begin{abstract}
Background: The rate of and the reasons for the failure of metal-on-metal (MoM) bearings have recently been discussed in literature. The aim of this study was to evaluate the influence of acetabular cup inclination and version angles on revision risk in patients with MoM hip arthroplasty. Methods: We retrospectively reviewed 825 patients (976 hips) who underwent a MoM hip arthroplasty between 2000 and 2013 . There were 474 men and 351 women, with a mean age of 58 (19-86) years. Acceptable cup orientation was considered to be inside the Lewinnek's safe zone.

Results: The mean acetabular inclination angle was 48.9 (standard deviation, 8.1; range, 16-76) and version angle 20.6 (standard deviation, 9.9; range, 25 to 46$)$. The cup was found to be outside the Lewinnek's safe zone in 571 hips $(58.5 \%)$. Acetabular cup revision surgery was performed in 157 hips $(16.1 \%)$. The cup angles were outside Lewinnek's safe zone in $69.2 \%$ of the revised hips. The mean interobserver reliability and intra-observer repeatability of the measurements of cup inclination and version angles were excellent (intraclass correlation coefficients $>0.90$ ). The odds ratio for revision in hips outside vs inside the Lewinnek's safe zone was 1.82 (95\% confidence interval, 1.26-2.62; P 1/4 .0014). Conclusion: Our findings provide compelling evidence that a cup position outside the Lewinnek's safe zone is associated with increased revision risk in patients with MoM arthroplasty.
\end{abstract}

\section{Introduction}

Improper acetabular cup orientation following total hip arthroplasty is associated with a risk of postoperative complications including dislocation, pain, altered range of motion, impingement, and even component failure [1-7]. A widely accepted safe zone suggested by Lewinnek for acetabular angles is $30-50$ of inclination and 5-25 of version [8]. Within this zone, dislocation tendency and component wear are balanced [1,8].

The rate of and reasons for the failure of metal-on-metal (MoM) bearings have recently been discussed in literature, including improper acetabular cup orientation. The usual cause for revisions in MoM hips are elevated metal ion concentrations, aseptic acetabular loosening [4], pseudotumors [9], aseptic lymphocyte-dominated vasculitis-associated lesions [7], fluid collection, and unexplained pain [4]. Some of these reasons are even found in non-symptomatic patients [4,10]. However, the association between pseudotumors and cup orientation has not been established [9]; therefore, patient selection might have a larger effect on pseudotumor formation than MoM bearings alone [5,9].

There are only a few articles reporting on the effect of component orientation and revision rate in addition to other complications [2,4-6,11-13]. To our knowledge, only one of these articles focused specifically on MoM bearings, reporting the results of 55 patients who had undergone revision of MoM hip resurfacing implants [13]. The purpose of our study was to evaluate the influence of acetabular cup inclination and version angles on revision risk in a large series of patients with MoM hip arthroplasty.

\section{Materials and methods}

A total of 976 MoM arthroplasties were performed between 2000 and 2013 in a single tertiary level center: 778 hips (80\%) and 176 hips (18\%) in 2 private hospitals, respectively, and $22(2 \%)$ in smaller hospitals. Data on 1068 hips were identified retrospectively from the patient databases of the hospitals between June and October of 2015. An exclusion criterion was the lack of X-ray im-agery, reducing the patient population to 825 patients (976 hips), of whom 474 (49\%) were men. Of these patients, 109 (13\%) patients had undergone bilateral MoM arthroplasty in either 1 or 2 stages. Information regarding implant model was available for 919 hips. Further analysis producing odds ratios (ORs) for 8 different component orientations were calculated based on these hips. Bimetric M2a-38 (524 [57.0\%]; Biomet, Warsaw, IL) and M2a- Magnum (200 [21.8\%]; Biomet, Warsaw, IL) were the most frequently used components. The mean age of all patients was $58(19-86)$ years at the time of surgery. Our mean follow-up period was 7.96 years $(1.7-15$ years $)$. 
Standard anteroposterior (AP) pelvic X-ray was used to measure acetabular cup inclination angle and lateral cross-table X-ray to measure the version angle. Cup orientation was measured from standard pelvic X-rays using lines between the cup edge, pelvic rami, and the vertical plane. Inclination measurement was taken by drawing a line between the lowest points of the pelvic rami and another line across the acetabular cup edge. Measurement of the orientation of acetabular component on plain AP radiographs has been found to be reliable and accurate [14]. Version angle was measured from lateral cross-table X-ray and was acquired by measuring the angle between the acetabular axel and a line perpendicular to the horizontal plane. The method was similar as described by Woo and Morrey [15]. The X-rays were obtained from a picture archiving and communication system and the angles were calculated digitally. The Lewinnek's safe zones of 30-50 of inclination and 5-25 on version were considered to be successful cup orientations [8]. One author (JTT) performed all of the measurements. Intraclass correlation coefficients between 2 authors (JTT and JLN, inter-rater) and within 1 author (JTT, intra-rater) were evaluated in 98 (10\%) randomly selected patients. Reasons for acetabular cup revision (metal reaction, osteolysis, dislocation, infection, painful joint, periprosthetic fracture, and a miscellaneous category for singular events) were recorded. Some of the reasons for revisions are clearly associated with MoM, for example, pseudotumor or osteolysis, but there are several complications, which have an increased risk due to MoM, for example, infection and dislocation. Therefore, due to lack of clear definition of MoM- related complications, all the reasons for revisions were included. Metal reaction was defined as the presence of elevated metal ions $(>5 \mathrm{mg} / \mathrm{L})$ or a pseudotumor; osteolysis was diagnosed when loss of bone around the components was mentioned in the patient's medical records and as infection if the same bacteria could be cultured in 2 or more periprosthetic specimens.

Scatter plots demonstrate the range and quantity of cup angles. Their percentages were calculated based on how many hips fell into the 9 different sections drawn on the charts. All figures are drawn in such a way that the x-axis represents the inclination angle and the y-axis represents version angle. The Lewinnek's safe zone is marked as a rectangle in the middle, and the corresponding proportion is calculated as a percentage in each segment.

\section{Statistical Analysis}

The tables and figures were drawn with and statistical analysis was performed with Excel 2011, v. 14.6.5 (Microsoft Inc, Redmond, WA) and SPSS v. 23.0 (IBM Corporation, Armonk, NY). Mean and 95\% confidence intervals for cup angles and ORs were calculated. The correlation between cup angle measurements was calculated using the Pearson's test and the association between cup angles and revision rate was calculated using the chisquare test. A P value of <.05 represents a statistically significant finding. All P values were 2 -sided.

\section{Results}

The mean acetabular inclination angle was 48.9 (standard deviation [SD], 8.1 ; range, 16 -76 ) and version angle 20.6 (SD, 9.9 ; range, 25 to 46 ). According to Lewinnek, the inclination was correctly installed in $58.5 \%$ of the hips and version in $67.3 \%$. The cup was found to be outside the Lewinnek's safe zone in

571 hips (58.5\%; Fig. 1). The mean interobserver reliability and intra-observer repeatability of the measurements of cup inclination and version angles were excellent (intraclass correlation co-efficients $>0.90$; Table 1).

Acetabular cup revision surgery was performed in 157 hips (16.1\%). In the revised hips, the cup angles were outside Lewinnek's safe zone in $69.2 \%$ (Fig. 2). Poor cup position increased the revision rate significantly in chi-square testing (P 1/4 .026). The OR for revision in hips outside the Lewinnek's safe zone compared to hips inside was 1.82 (95\% confidence interval, 1.26-2.62; P 1/4 .0014). In- crease in inclination angle or retroverted cup was associated with higher risk of revision (Table 2). The prevalence of hips that were inside the Lewinnek's safe zone in non-revised patients and revised patients is shown in Figures 1 and 2, respectively. Women had their cup angles inside the Lewinnek's safe zone in 38.6\% of the cases (n 1/4 169) and men in 44.1\% (n 1/4 238). Revision was more common in women than men (63.7\% [n 1/4 100] vs 26.3\% [n 1/4 57]).

The causes for revisions were a metal reaction in 96 of 157 cases $(61.1 \%)$, osteolysis in 24 (15.3\%), dislocation in 9 (5.7\%), infection in 9 (5.7\%), hip pain in $8(5.1 \%)$, periprosthetic fracture in $4(2.5 \%)$, and other reasons in $6(3.8 \%)$. In patients who had revision due to metal reaction, only $27.1 \%$ had cup angles inside the safe zone.

\section{Discussion}

Because MoM components have been reported to cause problems during clinical use, we assessed whether acetabular angles could increase revision risk. Our results show that only $40 \%$ of the cups were within the Lewinnek's safe zone and poor cup orientation led to increased revision risk (OR, 1.82).

The cup angles were outside of Lewinnek's safe zone in $58.5 \%$ of cases and located outside the center/in the upper right corner, with the inclination angles around 40 or greater and version of around 5 or greater (Fig. 1). Hart et al [4,13] and Matthies et al [9] reported a cluster of hips with cup 
angles in a similar location. This differs from the findings of Callanan et al [11] who reported that cup angles were more frequently in the Lewinnek's safe zone. Poor cup position increased the revision rate significantly (P 1/4 .026), which agrees with findings of other authors [1,13] (Table 3).

In our series, $16 \%$ of the patients underwent revision surgery. Cup angles within the Lewinnek's safe zone accounted for only $30.8 \%$ of the hips (Fig. 2), whereas the proportions in the 2 other studies were $6.6 \%$ [1] and 56.7\% [13], respectively (Table 3). How- ever, the sample populations were limited in these studies. Causes for revision varied greatly (Table 4). Interestingly, other authors have reported more revisions performed due to hip pain than in our study, but periprosthetic fractures seem to occur at similar frequencies. Table 4 illustrates that there is a lack of methodical reporting on MoM implants needing revision. Authors have focused on only 1 or 2 variables. The literature has mainly focused on cup orientation at a general level.

Complications related to improper cup angles are mechanical wear and increased metal ion levels, especially cobalt and chromium [1,7]. Inclination angles greater than 50 are associated with elevated metal ion levels because of increased component friction [1-7]. Surgical inexperience can predict higher inclination angles and, therefore, might increase dislocation and revision rates [11,13]. Other predictors of poor component orientation are minimally invasive surgical technique, body mass index $>30 \mathrm{~kg} / \mathrm{m}^{2}$, older age, gender, bone quality, and primary diagnosis $[2,8]$. Consistency in cup positioning methods and choosing individual values might reduce complications [12].

This study had a number of limitations. First, the data were collected retrospectively. Second, we did not include data on metal ion concentrations, Harris hip scores, and information about high- volume and low-volume surgeons. In addition, the cup measurements are prone to errors. Measurement of acetabular component inclination on plain AP radiographs has been found to be reliable and accurate [14]. Instead, the measurement of version from lateral cross-table X-ray is prone to errors due to effect of pelvic tilt. In cross-table X-rays, version has been reported to be average 3.8 ( \pm 13 for 95\% of the cases) lower than in computer tomography (CT), but there is a strong correlation between version determined from CT scans and crosstable images [16,17]. Despite these limitations, we considered that the margin of error was tolerable in the present study setting due to the relatively large number of patients. Acetabular inclination and version angles were measured digitally from AP and lateral hip X-rays, which represents a common clinical setting. Some investigators have used computed methods in the process [2,6,11] and others have used 3-dimensional CT scans or Xrays $[1,4,9,12]$. In our study, the interobserver reliability and intra-observer repeatability of the inclination and version angle measurements were excellent. Abdel et al [12] used a similar method in their investigation and also reported good inter-rater and intra-rater correlations. Furthermore, we attempted to assess the impact of different implant designs on complication rate. However, the small number of cases prevented us from making conclusive observations. Indeed, implant design [18] and small femoral head size [19] have been shown to be significantly associated with increased metal ion concentrations in patients undergoing MoM total hip arthroplasty.

\section{Conclusions}

Our findings provide compelling evidence that cup position outside the Lewinnek's safe zone is associated with increased revision risk in patients with MoM hip arthroplasty.

\section{References}

1. [1] Nikolaou VS, Petit A, Debiparshad K, Huk OL, Zukor DJ, Antoniou J. Metal-on- metal total hip arthroplasty - five- to 11-year follow-up. Bull NYU Hosp Jt Dis 2011;69(Suppl 1):S77e83.

2. [2] Bernstein M, Gupta S, Petit A, Zukor DJ, Huk OL, Antoniou J. The effect of operative factors on outlier ion levels in patients with metal-on-metal hip arthroplasties. Bull NYU Hosp Jt Dis 2011;69(Suppl 1):S20e6.

3. [3] Scheerlinck T. Cup positioning in total hip arthroplasty. Acta Orthop Belg 2014;80:336e47.

4. [4] Hart AJ, Sabah S, Henckel J, Lewis A, Cobb J, Sampson B, et al. The painful metal-on-metal hip resurfacing. J Bone Joint Surg Br 2009;91:738e44.

5. [5] Kuzyk PR, Sellan M, Olsen M, Schemitsch EH. Hip resurfacing versus metal-on- metal total hip arthroplasty - are metal ion levels different? Bull NYU Hosp Jt Dis 2011;69(Suppl 1):S5e11.

6. [6] De Haan R, Pattyn C, Gill HS, Murray DW, Campbell PA, De Smet K. Correlation between inclination of the acetabular component and metal ion levels in metal-on-metal hip resurfacing replacement. J Bone Joint Surg Br 2008;90: $1291 \mathrm{e}$.

7. Fabi D, Levine B, Paprosky W, Della Valle C, Sporer S, Klein G, et al. Metal-on-metal total hip arthroplasty: causes and high incidence of early failure. Orthopedics 2012;35:e1009e16.

8. Lewinnek GE, Lewis JL, Tarr R, Compere CL, Zimmerman JR. Dislocations after total hip-replacement arthroplasties. J Bone Joint Surg Am $1978 ; 60: 217 \mathrm{e} 20$

9. Matthies AK, Skinner JA, Osmani H, Henckel J, Hart AJ. Pseudotumors are common in well-positioned low-wearing metal-on-metal hips. Clin Orthop Relat Res 2012;470:1895e906.

10. Kwon YM, Ostlere SJ, McLardy-Smith P, Athanasou NA, Gill HS, Murray DW. "Asymptomatic" pseudotumors after metal-on-metal hip resurfacing arthroplasty: prevalence and metal ion study. J Arthroplasty 2011;26:511e8.

11. Callanan MC, Jarrett B, Bragdon CR, Zurakowski D, Rubash HE, Freiberg AA, et al. The John Charnley Award: risk factors for cup malpositioning: quality improvement through a joint registry at a tertiary hospital. Clin Orthop Relat Res 2011;469:319e29. 
12. Abdel MP, von Roth P, Jennings MT, Hanssen AD, Pagnano MW. What safe zone? The vast majority of dislocated THAs are within the Lewinnek safe zone for acetabular component position. Clin Orthop Relat Res 2016;474: 386e91.

13. Hart AJ, Matthies A, Henckel J, Ilo K, Skinner J, Noble PC. Understanding why metal-on-metal hip arthroplasties fail: a comparison between patients with well-functioning and revised Birmingham hip resurfacing arthroplasties. AAOS exhibit selection. J Bone Joint Surg Am 2012;94:e22.

14. Lu M, Zhou YX, Du H, Zhang J, Liu J. Reliability and validity of measuring acetabular component orientation by plain anteroposterior radiographs. Clin Orthop Relat Res 2013;471:2987.

15. Woo RY, Morrey BF. Dislocations after total hip arthroplasty. J Bone Joint Surg Am 1982;64:1295e306.

16. Reikeras O, Gunderson RB. Cross table lateral radiography for measurement of acetabular cup version. Ann Transl Med 2016;4:169.

17. Nunley RM, Keeney JA, Zhu J, Clohisy JC, Barrack RL. The reliability and vari- ation of acetabular component anteversion measurements from cross-table lateral radiographs. J Arthroplasty 2011;26(6 Suppl):84e7.

18. Mathary GS, Berryman F, Brash L, Pynsent PB, Treacy RB, Dunlop DJ. Influence of implant design on blood metal ion concentrations in metal-on-metal total hip replacement patients. Int Orthop 2015;39:1803e11.

19. Ando W, Yamamoto K, Atsumi T, Tamaoki S, Oinuma K, Shiratsuchi H. Comparison between component designs with different femoral size in metal-onmetal total hip arthroplasty; multicenter randomized prospective study. J Orthop 2015;12:228e36. 
Table 1

Intraclass Correlation Coefficients (ICC) Between 2 Assessors (TJTT and JLN InterRater) and Within 1 Assessor (TJTT, Intra-Rater).

\begin{tabular}{llllll}
\hline \multirow{2}{*}{ Cup Orientation } & \multicolumn{2}{l}{ ICC Inter-Rater } & & \multicolumn{2}{l}{ Intra-Rater } \\
\cline { 2 - 3 } \cline { 5 - 6 } \cline { 5 - 6 } & ICC & $95 \%$ Confidence Interval & & ICC & $95 \%$ Confidence Interval \\
\hline Inclination & 0.90 & $0.84-0.93$ & 0.96 & $0.95-0.98$ \\
Version & 0.96 & $0.94-0.97$ & 0.97 & $0.91-0.99$ \\
\hline
\end{tabular}

All 4 P values were $<.0001$.

Table 2

Odds Ratios (ORs) for Revision Between Suboptimal Cup Orientations and the Lewinnek's Safe Zone.

\begin{tabular}{llll}
\hline \multirow{2}{*}{ Version angle } & \multicolumn{3}{l}{ Inclination Angle } \\
\cline { 2 - 4 } & $<30^{\circ}(\mathrm{OR}[95 \% \mathrm{CI}])$ & $30^{\circ}-50^{\circ}$ & $>50^{\circ}$ \\
\hline$>25^{\circ}$ & $3.70(0.3-41.7)$ & $0.80(0.4-1.6)$ & $2.29^{*}(1.4-3.8)$ \\
$5^{\circ}-25^{\circ}$ & $1.23(0.2-10.5)$ & Reference & $1.65^{*}(1.1-2.6)$ \\
$<5^{\circ}$ & $2.45(0.1-61.0)$ & $3.54^{*}(1.6-7.8)$ & $1.65(0.3-7.9)$ \\
\hline
\end{tabular}

Presented values are ORs for revision with $95 \% \mathrm{CI}$ in parentheses. ${ }^{*} P<.05$.

$\mathrm{CI}$, confidence interval.

Table 3

Comparison of Cup Orientations Between References.

\begin{tabular}{|c|c|c|c|c|}
\hline Author and Year & Mean Inclination & Mean Version & Inside Lewinnek's Safe Zone & Revision \\
\hline Nikolaou et al, 2011 [1] & $40.1^{\circ} \pm 7.5^{\circ}$ & $16.8^{\circ} \pm 8.7^{\circ}$ & $88.6 \%$ & $6.6 \%$ \\
\hline Bernstein et al, 2011 [2] & $45.4^{\circ \mathrm{a}}$ & $18.7^{\circ \mathrm{a}}$ & $\mathrm{N} / \mathrm{A}$ & $\mathrm{N} / \mathrm{A}$ \\
\hline Hart et al, 2009 [4] & $55^{\circ}$ & $31^{\circ}$ & $18.8 \%$ & $\mathrm{~N} / \mathrm{A}$ \\
\hline Kuzyk et al, 2011 [5] & $45.2 \%{ }^{\mathrm{b}}$ & $\mathrm{N} / \mathrm{A}$ & $\mathrm{N} / \mathrm{A}$ & $\mathrm{N} / \mathrm{A}$ \\
\hline De Haan et al, 2008 [6] & $\mathrm{N} / \mathrm{A}$ & N/A & $65.4 \%$ & $\mathrm{~N} / \mathrm{A}$ \\
\hline Callanan et al, 2011 [11] & $42.2^{\circ} \pm 6.8^{\circ}$ & $12.7^{\circ} \pm 7.4^{\circ}$ & $47 \%^{\mathrm{c}}$ & $\mathrm{N} / \mathrm{A}$ \\
\hline Matthies et al, 2012 [9] & $47^{\circ \mathrm{d}}-10$ & $18^{\text {od }}$ & $\mathrm{N} / \mathrm{A}$ & $\mathrm{N} / \mathrm{A}$ \\
\hline Abdel et al, 2015 [12] & $44^{\circ} \pm 8^{\circ}$ & $15^{\circ} \pm 9^{\circ}$ & $58 \%$ & $\mathrm{~N} / \mathrm{A}$ \\
\hline Hart et al, 2012 [13] & $\mathrm{N} / \mathrm{A}$ & $\mathrm{N} / \mathrm{A}$ & $45 \%^{\mathrm{e}}$ and $38 \%$ & $56.7 \%$ \\
\hline Our study & $48.9^{\circ} \pm 0.55^{\circ}$ & $20.6^{\circ} \pm 0.66^{\circ}$ & $41.5 \%$ & $16.1 \%$ \\
\hline
\end{tabular}

N/A, not available.

${ }^{\text {a }}$ Mean of multiple values.

b Meta-analysis, mean of multiple articles.

${ }^{c}$ Safe zone was $5^{\circ}-25^{\circ}$ and $30^{\circ}-45^{\circ}$.

d Mean of multiple values.

e Hips with revision.

Table 4

Comparison of Diagnoses Leading to a Revision Surgery.

\begin{tabular}{|c|c|c|c|c|c|c|c|}
\hline Author and Year & Metal Reaction & Osteolysis/Aseptic Loosening & Dislocation & Infection & Pain & Fracture & Failure \\
\hline Nikolaou et al, 2011 [1] & N/A & $7.7 \%$ & N/A & $7.7 \%$ & N/A & N/A & $77 \%^{\mathrm{a}}$ \\
\hline Fabi et al, 2012 [7] & $6.25 \%$ & $56.3 \%$ & N/A & $12.5 \%$ & & $5 \%$ & $6.25 \%$ \\
\hline Matthies et al, 2012 [9] & $\mathrm{N} / \mathrm{A}$ & $14.3 \%$ & N/A & $\mathrm{N} / \mathrm{A}$ & $73.4 \%$ & $2.9 \%$ & $\mathrm{~N} / \mathrm{A}$ \\
\hline Abdel et al, 2015 [12] & N/A & $\mathrm{N} / \mathrm{A}$ & $2.1 \%$ & $\mathrm{~N} / \mathrm{A}$ & $\mathrm{N} / \mathrm{A}$ & $\mathrm{N} / \mathrm{A}$ & $\mathrm{N} / \mathrm{A}$ \\
\hline Hart et al, 2012 [13] & N/A & $21.8 \%$ & $\mathrm{~N} / \mathrm{A}$ & $\mathrm{N} / \mathrm{A}$ & $69.1 \%$ & $3.6 \%$ & $\mathrm{~N} / \mathrm{A}$ \\
\hline Our study & $61.1 \%$ & $15.3 \%$ & $5.7 \%$ & $5.7 \%$ & $5.1 \%$ & $2.5 \%$ & $0.6 \%$ \\
\hline
\end{tabular}

N/A, not available.

a The authors suspected an error during the manufacturing process to be the cause. 


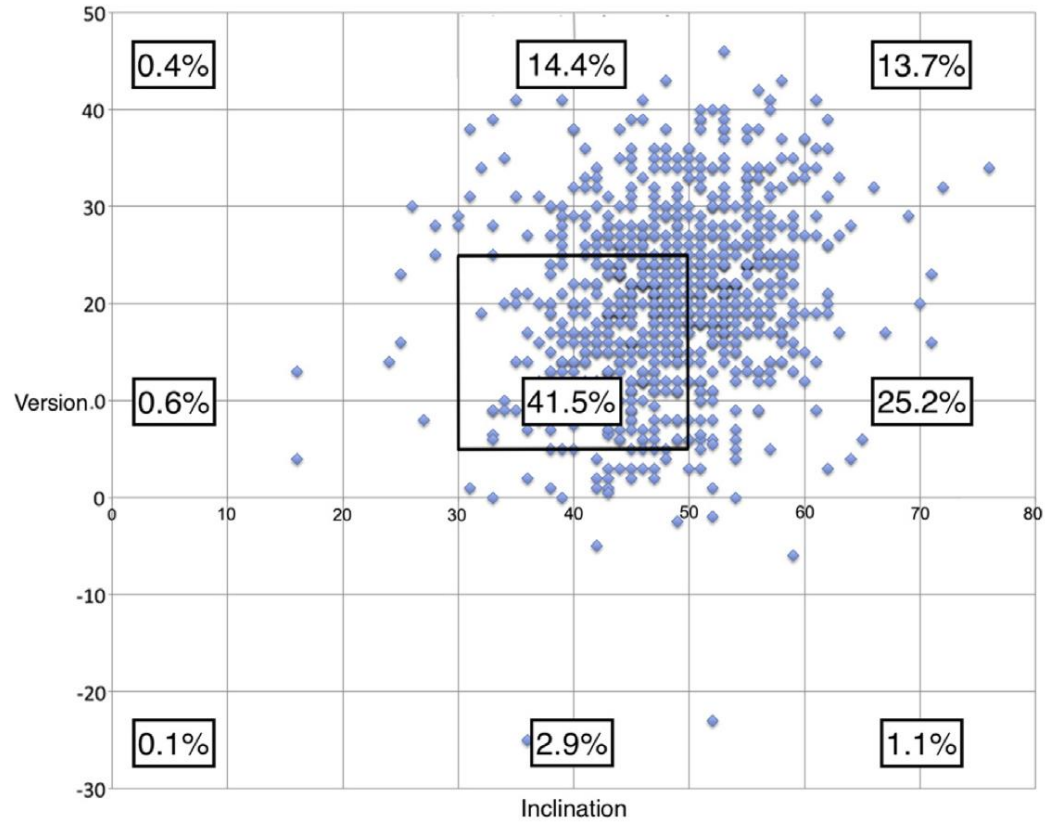

Fig. 1. Cup orientations in patients who did not need revision $(n=819)$.

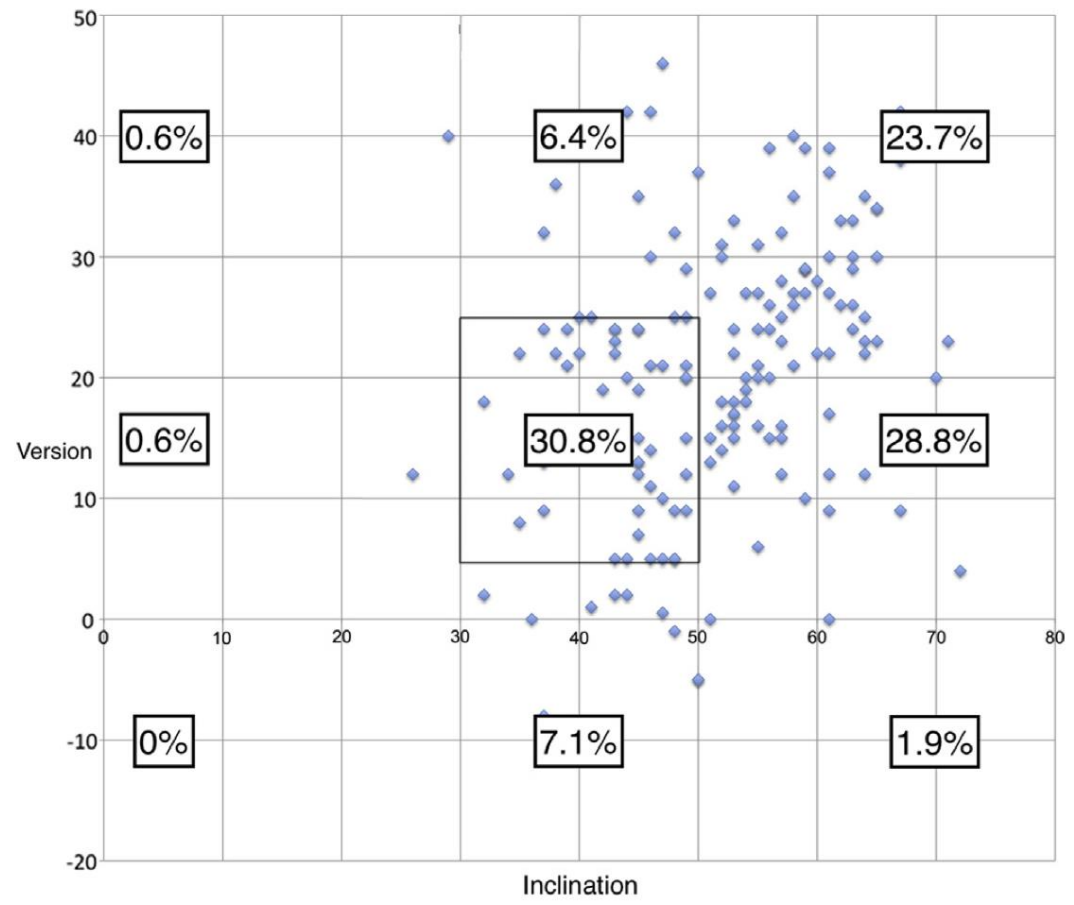

Fig. 2. Cup orientations in patients who required revision $(n=157)$. 